\title{
MICROEXTRAÇÃo POR FASE SÓLIDA
}

\author{
Antonio Luiz Pires Valente* e Fabio Augusto \\ Instituto de Química - Universidade Estadual de Campinas - CP 6154 - 13083-970 - Campinas - SP
}

Recebido em 22/10/98; aceito em 8/10/99

\begin{abstract}
SPME, SOLID PHASE MICRO-EXTRATION. Fundamental aspects of Solid Phase Micro-Extraction (SPME) are discussed in the present paper. The application of SPME as a microtechnique of sample preparation for gas chromatographic analysis is considered and related to existing theoretical models. Both research prototypes and commercial SPME devices are considered.
\end{abstract}

Keywords: solid phase micro-extraction (SPME); sample preparation; solventless analyte extraction.

\section{INTRODUÇÃO}

A qualidade de um método analítico é determinada, como representado na Figura 1, pela qualidade de suas etapas, com seus erros experimentais. Por um lado, esta qualidade depende da técnica de amostragem, com a qual seleciona-se uma fração presumivelmente representativa da amostra primária. Nesta fração devem-se identificar e quantificar analitos, que são os componentes químicos que, também presumivelmente, a definem. É comum não se analisar quimicamente matrizes na forma bruta, pois elas costumam ter e gerar interferências e incompatibilidades com equipamentos analíticos. Para contornar tais problemas são empregados procedimentos de preparo da amostra, com os quais procura-se isolar e concentrar os analitos a níveis adequados e obter um nível de limpeza da amostra que não comprometa a sua análise química. Portanto, o preparo da amostra também inclui a sua compatibilização com a técnica que fornecerá os dados químicos. A SPME é uma opção relativamente recente ${ }^{1}$, que tem sido empregada para essas operações que criam o elo entre a matriz química e o instrumental analítico, sendo particularmente interessante para Cromatografia Gasosa.

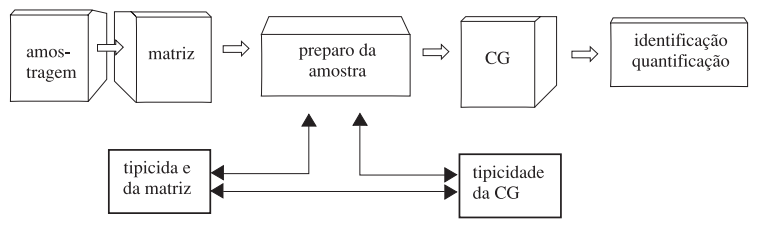

processos de convalidação que envolvem avaliações estatísticas sobre todas as etapas

Figura 1. Etapas num processo analítico visando a análise química por $C G$.

O intensivo uso da Cromatografia Gasosa (CG) e os consequentes desenvolvimentos tecnológicos resultaram numa poderosa técnica de separação que possibilita a detecção de analitos virtualmente puros ${ }^{2}$. Em outros termos, a CG prepara de forma admirável os analitos para identificação e quantificação. Como técnica analítica ela depende da qualidade da etapa de preparo da amostra, pois quase nenhuma matriz pode ser diretamente injetada num cromatógrafo gasoso. Este é o caso típico de análise de matrizes de origem ambiental, que via de regra contém além de particulados não voláteis, termodegradáveis, etc, água em quantidades incompatíveis com as colunas cromatográficas e detectores de CG. Portanto, a viabilização da análise por CG depende de um método adequado de preparo da amostra. Um destes métodos é a SPME, porque não utiliza solvente, tem alto poder de concentração (adequando-se com as sensibilidades dos detectores de CG), é aplicável a muitos tipos de analitos e facilita o transporte do material extraído para o cromatógrafo ${ }^{3,4}$

\section{O QUE É SPME?}

SPME é uma microtécnica, em que os processos de extração e pré-concentração de analitos ocorrem numa escala dimensional que não é das mais usuais. O dispositivo básico de SPME consiste de um bastão de fibra ótica, de sílica fundida (FS) de $100 \mathrm{~mm}$ de diâmetro, com $10 \mathrm{~mm}$ de uma extremidade recoberto com um filme fino de um polímero (e.g., polidimetilsiloxano $=$ PDMS, poliacrilato $=$ PA ou Carbowax $=$ Cwx) ou de um sólido adsorvente (e.g., carvão ativo microparticulado $=$ Carboxen $)^{5}$. O detalhe da Figura $2 \mathrm{~B}$ representa uma fibra comercial em que o recobrimento, ou filme extrator, tem espessura de $100 \mu \mathrm{m}$.

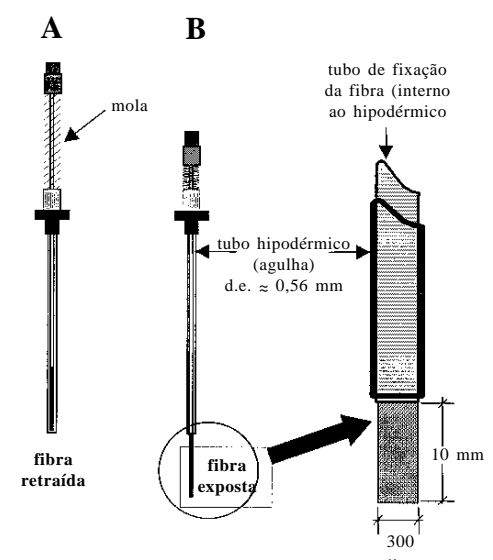

Figura 2. Dispositivo da fibra de SPME: (A) Posição com a fibra retraída na agulha (tubo hipodérmico de diâmetro externo $0,56 \mathrm{~mm}$ ), (B) posição com a fibra exposta. No detalhe são mostradas as dimensões típicas da seção com recobrimento de $100 \mu \mathrm{m}$ de espessura.

As espessuras dos recobrimentos, $\mathrm{L}_{\mathrm{f}}$, de fibras comerciais variam de $7 \mu \mathrm{m}$ a $100 \mu \mathrm{m}$ e seus volumes de $0,03 \mu \mathrm{L}$ a 0,7 $\mu \mathrm{L}^{4,6}$. A extração ocorre mergulhando-se a seção recoberta na amostra, ou no seu "headspace". As seguintes considerações ilustram as vantagens da microescala de extração. Imagine-se uma gotícula, de $1 \mu \mathrm{L}$, de solvente orgânico, colocada em $10 \mathrm{ml}$ 
$(10.000 \mu \mathrm{L})$ de uma matriz aquosa com analitos orgânicos. Esta gotícula de solvente representaria um décimo milésimo do volume da matriz. Por afinidade, analitos orgânicos migrariam da matriz para a gotícula de solvente onde seriam concentrados de acordo com seus coeficientes de partição entre o solvente orgânico e a matriz aquosa. Para fins quantitativos, depois de saturada com os analitos, a gotícula de $1 \mu \mathrm{L}$ teria de ser retirada intacta do seio da matriz - onde ela deveria ser imiscível, mesmo sob agitação - e injetada para Cromatografia Gasosa. O volume da gota e o nível de concentração dos analitos resultariam num cromatograma em que a superposição dos analitos à cauda do pico do solvente não comprometeria a análise quantitativa. A microescala apresentaria mais uma vantagem: como, comparativamente à matriz, em cada gota haveria pouco analito, as pequenas quantidades extraídas não descacterizariam as correspondentes concentrações na matriz. Desta forma, outras extrações poderiam ser realizadas na mesma matriz, para dispor de replicatas estatisticamente confiáveis. Entretanto, na forma descrita acima, este procedimento seria inviável pelas dificuldades experimentais inerentes, por exemplo, à manipulação de volumes tão pequenos de solvente. Na SPME o recobrimento da fibra age de modo similar à gotícula do exemplo acima; entretanto, por estar imobilizado no suporte de FS, a sua introdução e remoção quantitativa da matriz é facilitada, contornando grande parte dos problemas práticos associados ao exemplo discutido. Porém, sob os demais aspectos a SPME mantém todas as demais complexidades inerentes aos métodos de extração convencionais.

Realizada a extração, a fibra é retirada da amostra e inserida no injetor do cromatógrafo gasoso, onde os analitos são termicamente dessorvidos sob fluxo do gás de arraste e carregados para a coluna cromatográfica. Com as dimensões antes mencionadas as fibras extraem pequenas quantidades de analito, o que facilita sua dessorção e subsequente separação cromatográfica. As fibras são frágeis, razão pela qual o dispositivo mostrado na Figura 2 foi projetado para que ela possa ser retraída para dentro do tubo hipodérmico durante operações que possam danificá-las (Figura 2A), tais como a de transporte e as de perfurar o septo do frasco de amostra e o do injetor do cromatógrafo. A operação completa para extração e dessorção para análise cromatográfica é descrita a seguir.

\section{DESCRIÇÃO E USO DO SISTEMA DE SPME COMERCIAL}

Com o dispositivo da fibra (Figura 2) e o amostrador (uma espécie de seringa, Figura 3) o manuseio das fibras para extração é bastante facilitado. O dispositivo da fibra, que não pode ser manipulado diretamente, é usado com o amostrador onde, como mostrado na Figura 3, a fibra é presa a um êmbolo. $\mathrm{Na}$ extremidade oposta ao êmbolo, o tubo hipodérmico fica exposto, pois além de proteger a fibra ele é a agulha com que são perfurados septos. Na Figura 3B é mostrado que no corpo do amostrador existe uma fenda em forma de " $Z$ ", na qual corre um pino que, preso ao êmbolo, guia o seu deslocamento. No movimento de exposição da fibra, quando o pino atinge o corte transversal da fenda (Figura 3B), um pequeno giro do êmbolo trava a fibra na posição "exposta".

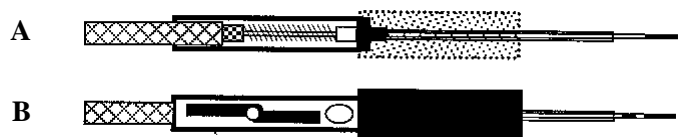

Figura 3. (A) Vista interna do amostrador de SPME com a fibra exposta; (B) vista com a fibra exposta e o êmbolo travado pelo pino no centro da fenda em " $Z$ ".

A sequência de procedimentos para realizar a extração e a dessorção no injetor do cromatógrafo é mostrada na Figura 4

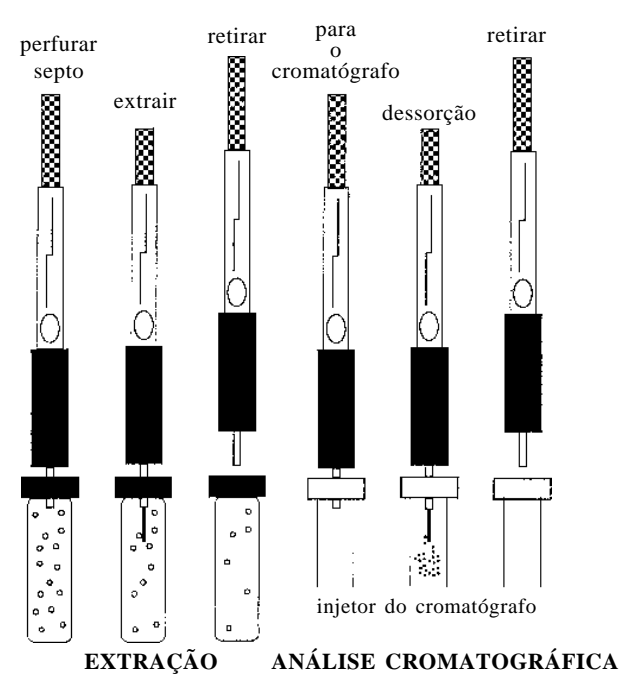

Figura 4. Uso do amostrador de SPME para o processo de extração e o de dessorção do material extraído para análise por CG.

Com a fibra retraída na agulha, o septo do frasco de amostra é perfurado e a fibra é exposta à amostra. Terminado o tempo de extração a fibra é novamente retraída, a agulha é retirada do septo e levada para inserção no CG. Com a fibra retraída o septo do injetor é perfurado, a fibra é exposta para dessorção térmica e, terminada a dessorção, é retraída e a agulha retirada. Após o procedimento é altamente recomendável vedar a agulha com um pedaço de septo, para evitar contaminações da fibra, o que também auxilia amostrar em locais distantes e transportar o conjunto para o laboratório 4 .

As fibras disponíveis comercialmente para CG estão relacionadas na Tabela 1. As sugestões de aplicações desta tabela são necessariamente genéricas, pois as fibras relacionadas foram desenvolvidas para uso geral. Fibras para problemas específicos ainda não são comercializadas?

\section{FUNDAMENTOS DA TEORIA DA SPME}

Numa extração por SPME as moléculas do analito tem de se deslocar da matriz e penetrar no recobrimento e, para isto, resistências a transferências de massa devem ser vencidas, até que se estabeleça um equilíbrio de partição (ou de adsorção, para o caso de recobrimentos sólidos) do analito, entre a fibra e o meio que a envolve. Portanto, a teoria de SPME baseia-se na cinética de transferência de massa entre fases e na termodinâmica que descreve o equilíbrio de partição do analito entre elas. A discussão teórica, apresentada sequenciadamente em vários artigos é extensa, de tal forma que agrupada em livro sobre a técnica ${ }^{3}$, cobre 72 páginas. Aqui esta discussão foi substancialmente abreviada.

\section{O EQUILÍbRIO DE PARTIÇÃo EM SPME}

A SPME é um processo baseado em equilíbrios simultâneos em sistemas multifásicos. Um sistema trifásico ideal simples é o de uma fibra mergulhada numa matriz aquosa com um headspace; sistemas reais são mais complexos pois, nem o headspace nem a matriz são soluções ideais, os analitos podem interagir entre si, com as paredes do frasco e eventualmente com o bastão de sílica fundida da fibra. Os fundamentos da distribuição de massas na extração podem ser descritos a partir do que ocorreria num sistema ideal trifásico: antes da extração, $\mathrm{n}_{0}$ moles do analito estariam presentes, com uma concentração $\mathrm{C}_{0}$, em um volume $\mathrm{V}_{\mathrm{m}}$ da matriz ${ }^{8}$; quando completada a extração, os $n_{0}$ moles se distribuiriam entre as fases, isto é, $n_{m}^{\mathrm{e}}$ na 
Tabela 1. Fibras de SPME disponíveis comercialmente $e^{4,5}$.

\begin{tabular}{|c|c|c|c|c|}
\hline Tipo $^{\mathrm{a}}$ & Composição Química & $\mathrm{L}_{\mathrm{f}} / \mu \mathrm{m}$ & $\Delta \mathrm{T}^{\circ} \mathrm{C}^{\mathrm{b}}$ & Aplicação sugerida \\
\hline Não-polares & Polidimetilasiloxano (PDMS) & $\begin{array}{l}100 \\
30 \\
7\end{array}$ & $\begin{array}{l}200-270^{\circ} \mathrm{C} \\
220-320^{\circ} \mathrm{C}\end{array}$ & $\begin{array}{l}\text { Basicamente para compostos apolares. } \\
\text { É possível usar com polares. }\end{array}$ \\
\hline Polares & $\begin{array}{l}\text { Poliacrilato (PA) } \\
\text { Carbowax/divinilbenzeno } \\
\text { (CW-DVB) }\end{array}$ & $\begin{array}{l}85 \\
65\end{array}$ & $\begin{array}{l}220-310^{\circ} \mathrm{C} \\
200-260^{\circ} \mathrm{C}\end{array}$ & $\begin{array}{l}\text { Medianamente a altamente polares, como } \\
\text { fenóis, pesticidas orgafosforados. Cetonas, } \\
\text { álcoois. Voláteis de média a alta polaridade. }\end{array}$ \\
\hline Bi-polares & $\begin{array}{l}\text { PDMS-DVB } \\
\text { Carboxen-PDMS }\end{array}$ & $\begin{array}{l}65 \\
75\end{array}$ & $200-270^{\circ} \mathrm{C}$ & $\begin{array}{l}\text { Voláteis e não voláteis de baixa a alta } \\
\text { polaridade. } \\
\text { Voláteis. }\end{array}$ \\
\hline
\end{tabular}

a. Não estão relacionadas fibras para Cromatografia Líquida. b. $\Delta \mathrm{T}^{\circ} \mathrm{C}=$ faixa de temperatura indicada dessorção.

matriz aquosa ( ${ }^{\mathrm{e}} \equiv$ equilíbrio), $\mathrm{n}_{\mathrm{h}}^{\mathrm{e}}$ no headspace e $\mathrm{n}_{\mathrm{f}}^{\mathrm{e}}$ na fibra. A conservação de massa no processo é expressada como:

$n_{0}=n_{m}^{e}+n_{h}^{e}+n_{f}^{e}$

Abaixo, a Equação 2 correlaciona as constantes de distribuição fibra-matriz, $\mathrm{K}_{\mathrm{fm}}=\mathrm{C}_{\mathrm{f}} \mathrm{e}^{\mathrm{e}}{ }_{\mathrm{m}}$, fibra-headspace, $\mathrm{K}_{\mathrm{fh}}=\mathrm{C}_{\mathrm{f}}$ / $\mathrm{C}_{\mathrm{h}}^{\mathrm{e}}$ e headspace-matriz, $\mathrm{K}_{\mathrm{hm}}=\mathrm{C}_{\mathrm{h}}{ }_{\mathrm{h}} / \mathrm{C}_{\mathrm{m}}^{\mathrm{e}}$; esta equação é obtida da Equação $1 \mathrm{com}$ as substituições dos volumes e concentrações das fases em equilíbrio, respectivamente, para a matriz, o headspace e a fibra, $\mathrm{V}_{\mathrm{m}}^{\mathrm{e}}$ e $\mathrm{C}_{\mathrm{m}}^{\mathrm{e}}, \mathrm{V}_{\mathrm{h}}^{\mathrm{e}}$ e $\mathrm{C}_{\mathrm{h}}^{\mathrm{e}}, \mathrm{V}_{\mathrm{f}}^{\mathrm{e}}$ e $\mathrm{C}_{\mathrm{f}}{ }^{\mathrm{e}}$ :

$K_{f m}=K_{f h} K_{h m}$

Após substituição das constantes de distribuição e da Equação 2 na Equação 1 e rearranjos algébricos, obtém-se a Equação $3^{9}$, que fornece a quantidade de analito extraído no sistema em equilíbrio.

$n_{f}^{e}=\frac{K_{f m} V_{f} C_{0} V_{m}}{K_{f m} V_{f}+K_{h m} V_{h}+V_{m}}$

Assim, a Equação 3 correlaciona a quantidade extraída do analito com os parâmetros fundamentais dos equilíbrios simultâneos e descreve o aspecto termodinâmico da SPME. Contudo, a Equação 3 não se relaciona com o intervalo de tempo necessário para atingir o equilíbrio. Este intervalo de tempo, que é fundamental do ponto de vista experimental, depende das dificuldades de transferência de massa no sistema.

\section{CONSIDERAÇÕES CINÉTICAS EM SPME}

A Equação 4, cujo desenvolvimento é detalhado $\mathrm{em}^{10}$, expressa o tempo para atingir o equilíbrio, $t_{e}$, em função da espessura do recobrimento $\left(\mathrm{L}_{\mathrm{f}}\right)$ e do coeficiente de difusão do soluto nessa camada $\left(\mathrm{D}_{\mathrm{f}}\right)$.

$\mathrm{t}_{\mathrm{e}} \approx \mathrm{t}_{95}=\frac{\mathrm{L}_{\mathrm{f}}^{2}}{2 \mathrm{D}_{\mathrm{f}}}$

Segundo esta equação, o tempo necessário para atingir o equilíbrio seria infinito mas, devido às incertezas experimentais inerentes às extrações por SPME, considera-se, como mostrado na Equação 4, um tempo de equilíbrio prático, t ${ }_{95}$, que correspondente à extração de $95 \%$ da massa que seria extraída após um tempo infinito de extração.

A correlação do modelamento pela Equação 4 com a situação experimental precisa ser avaliada com cautela. Por exemplo, quando nela são substituídos os parâmetros para a fibra com o recobrimento mais espesso comercialmente disponível
$\left(\mathrm{PDMS}, \mathrm{L}_{\mathrm{f}}=100 \mu \mathrm{m}\right)$ e um analito como benzeno, de $\mathrm{D}_{\mathrm{f}}=2,8$ x $10^{-6} \mathrm{~cm} \cdot \mathrm{s}^{-1}$, é previsto que $t_{95}$ seria cerca de 20 segundos ${ }^{11}$. $\mathrm{Na}$ prática este valor só é aproximado quando a extração do benzeno é feita de uma matriz gasosa ${ }^{12}$. Em extrações de matrizes aquosas, o tempo necessário ao trânsito do analito pela matriz até atingir a superfície da fibra teria de ser considerado; neste caso o $\mathrm{t}_{\mathrm{e}}$ é de $200 \mathrm{~s}$ ou mais ${ }^{11}$ (Figura 5).

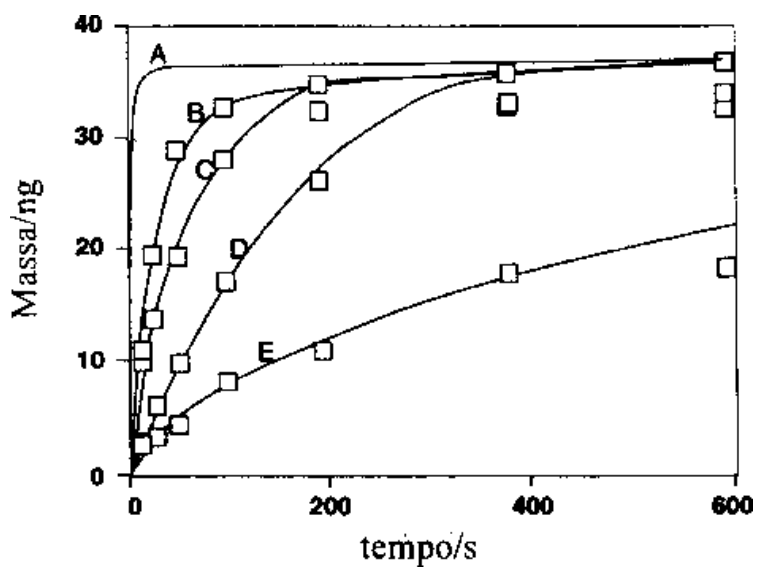

Figura 5. Perfis de extração para 1 ppm de benzeno em água, (A) segundo o modelamento pela Equação 4 (usando-se $K_{f m}=125, D_{f}=$ $2,8 \times 10^{-6} \mathrm{~cm} \cdot \mathrm{s}^{-1}$ e $\left.D_{m}=1,08 \times 10^{-5} \mathrm{~cm}_{\mathrm{s}} \mathrm{s}^{-1}\right)$, sob três condições de agitação: (B) agitação magnética a $2500 \mathrm{rpm}$, (C) $1800 \mathrm{rpm}$, (D) $400 \mathrm{rpm}$ $e(E)$ sem agitação. Agitador magnético de $7 \mathrm{~mm}$ de comprimento, frasco de 7,4 ml, fibra de $L_{f}=0,56 \mathrm{~mm}$ posicionada no centro do frasco.

Na Figura 5 são mostradas cinco perfis de extração (curvas correlacionando fração extraída com tempo de extração), do benzeno com fibra PDMS. A curva A é teórica e representa o comportamento segundo a Equação 4; as demais curvas são experimentais, com vários níveis de agitação da matriz aquosa (curvas B, C, D) e sem agitação (curva E). Comparando-se as curvas experimentais nota-se que o $t_{e}$ diminui com o aumento da agitação da matriz, porque este procedimento facilita o contacto do analito com a fibra. No entanto, mesmo sob agitação o $t_{\mathrm{e}}$ é substancialmente menor do que o previsto pela Equação 4. Isto ocorre porque apesar da agitação, a superfície da fibra fica em contacto com uma camada estática da matriz, de espessura $\delta$, onde não existe agitação (Figura 6).

Ao contrário do que ocorre na região agitada, na camada estática a transferência de massa ocorre exclusivamente por difusão e, portanto, é mais lenta. Na Equação 5 o produto $\delta \mathrm{K}_{\mathrm{fm}} \mathrm{L}_{\mathrm{f}}$ relaciona os fatores responsáveis pelo retardamento de $t_{e}$, pois $o$ tempo para equilíbrio é incrementado com o aumento da camada estática, da espessura do recobrimento da fibra e de $\mathrm{K}_{\mathrm{fm}}$, que dimensiona a quantidade de analito necessária para ser atingida 


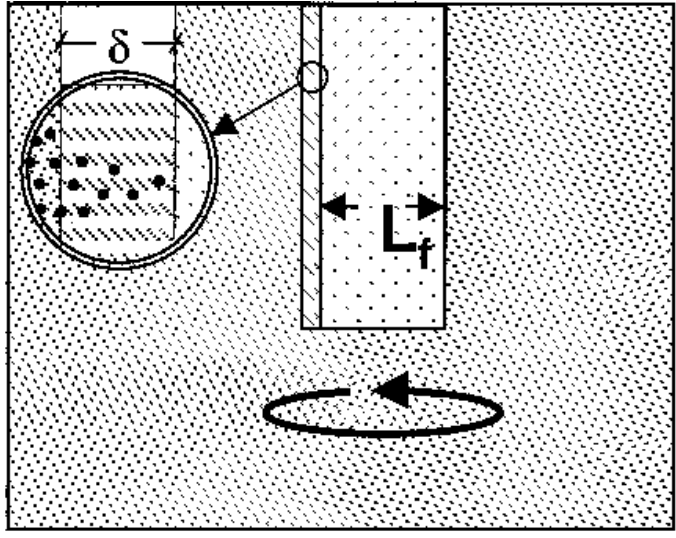

Figura 6. Extração SPME direta com agitação prática. $d=$ espessura da camada estática (não agitada).

a concentração de equilíbrio na fibra ${ }^{13}$. A Equação 5 aplicada à extração do benzeno de água resulta numa previsão de $t_{\mathrm{e}}=190$ $\mathrm{s}^{14}$, próxima dos resultados mostrados na Figura 5.

$\mathrm{t}_{\mathrm{e}} \approx \mathrm{t}_{95}=3 \delta \frac{\mathrm{K}_{\mathrm{fm}} \mathrm{L}_{\mathrm{f}}}{\mathrm{D}_{\mathrm{m}}}$

A Equação 5 tem implicações experimentais importantes na extração direta com agitação. Uma delas é a de que o tempo para atingir o equilíbrio é mais dependente da difusão do soluto na camada aquosa estacionária $\left(D_{m}\right)$ do que na fibra. Além disto, fibras com recobrimentos menos espessos são convenientes para extrações mais rápidas (deve-se, porém considerar que com recobrimentos finos a quantidade de material extraído é menor, o que pode limitar a sensibilidade analítica).

As discussões anteriores enfocaram os fundamentos da SPME direta em matrizes aquosas e gasosas. A SPME também pode ser usada para extrações do headspace, como discutido a seguir. Nestas extrações, a transferência de massa num sistema trifásico fibra-headspace-matriz depende dos equilíbrios de partição entre as três fases, das dimensões das fases e dos coeficientes de difusão do soluto nelas. A correlação entre estes fatores e o tempo de equilíbrio, válida para extrações sem agitação é descrita pela Equação 6:

$t_{e} \approx t_{95}=1,8\left(\frac{L_{h}}{K_{h m} D_{h}}+\frac{L_{m}}{1,6 D_{m}}\right) K_{f m} L_{f}$

De acordo com esta equação, é conveniente minimizar as espessuras da matriz $\left(\mathrm{L}_{\mathrm{m}}\right)$, do headspace $\left(\mathrm{L}_{\mathrm{h}}\right)$ e da fibra $\left(\mathrm{L}_{\mathrm{f}}\right)$. As limitações para diminuição de $\mathrm{L}_{\mathrm{f}}$ foram comentadas anteriormente; uma excessiva diminuição de $\mathrm{L}_{m}$ também pode comprometer a sensibilidade do método e as diminuições de $\mathrm{L}_{\mathrm{m}} \mathrm{e}$ $\mathrm{L}_{\mathrm{h}}$ podem afetar negativamente a termodinâmica de extração, caso as concentrações do analito variem excessivamente no headspace e na matriz. Outros aspectos práticos prendem-se aos coeficientes de difusão e às constantes de equilíbrio de partição. Problemas com coeficientes de difusão desfavoráveis podem ser contornados com agitação e/ou aquecimento do sistema. Quanto às constantes de distribuição, o compromisso entre elas pode ser explorado com base na Figura 7.

$\mathrm{Na}$ Figura 7A estão representados, para analitos com $\mathrm{K}_{\mathrm{fh}} \approx$ 10.000 , os perfis de extração para $\mathrm{K}_{\mathrm{hm}}=0,2, \mathrm{~K}_{\mathrm{hm}}=0,02$ e $\mathrm{K}_{\mathrm{hm}}$ $=0,002^{15}$. Nota-se que o equilíbrio é atingido muito mais rapidamente para o maior valor de $\mathrm{K}_{\mathrm{hm}}$. Por outro lado, na Figura $7 \mathrm{~B}$, em que estão representados perfis de extração para $\mathrm{K}_{\mathrm{hm}}=0,2 \mathrm{e}$ $\mathrm{K}_{\mathrm{fh}}=100,1.000$ e 10.000 , é evidenciado que o equilíbrio é atingido mais rapidamente para o menor valor de $\mathrm{K}_{\mathrm{fh}}$. Portanto,
A
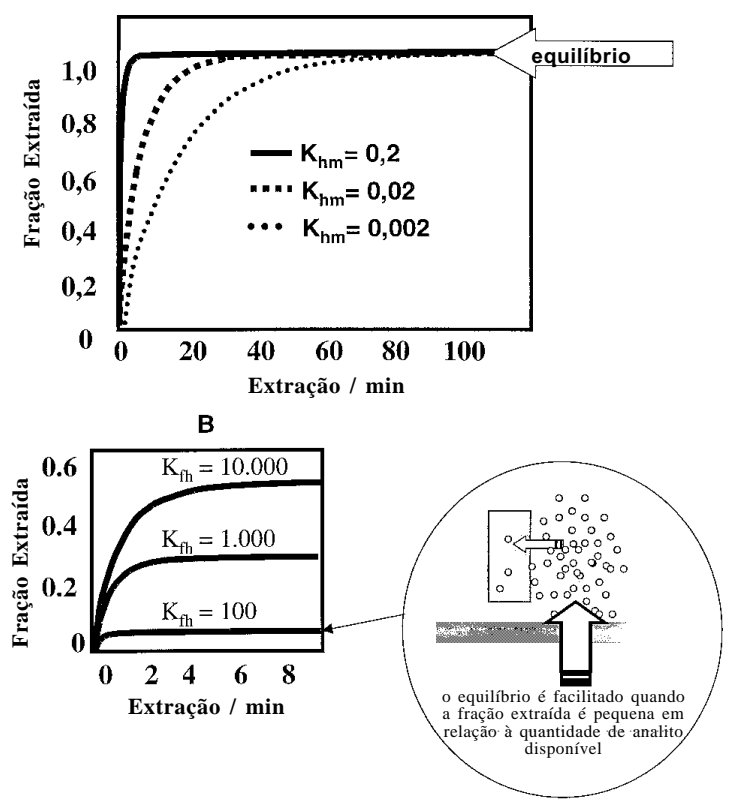

Figura 7. Correlações entre os $K_{h m}$ e $K_{f h}$ e os perfis de extração para analitos extraídos num sistema hipotético (adaptada de 15; detalhes no texto).

conforme o destaque na Figura 7B, conclui-se que a extração é favorecida para analitos que tenham, simultaneamente, $\mathrm{K}_{\mathrm{hm}}$ elevado e baixo $K_{f h}$, porque a concentração de analito na fibra é pequena em relação à sua concentração na $\operatorname{amostra}^{16}$ - o que ocorre na prática, pois os volumes dos recobrimentos das fibras são muito menores que os da amostra e do headspace.

Um exemplo interessante do efeito do valor de $\mathrm{K}_{\mathrm{fh}}$ é representado na Figura 8, em que são mostrados perfis de extração do headspace para benzeno e o-xileno.

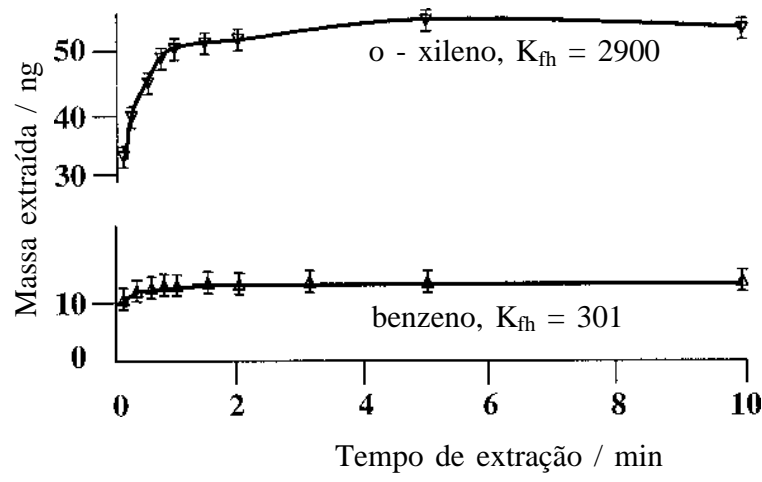

Figura 8. Perfiz de extração obtidos para SPME de headspace sob agitação, de solução aquosa com 1 ppm de benzeno e o-xileno (adaptada de 9).

Na Figura 8, o tempo de extração do benzeno é de cerca de $20 \mathrm{~s}$ e o do o-xileno aproximadamente $100 \mathrm{~s}$. Eles têm, respectivamente, pontos de ebulição iguais a $80^{\circ} \mathrm{C}$ e $144^{\circ} \mathrm{C}$. A maior volatilidade do benzeno torna mais fácil a sua passagem para o headspace. Ao mesmo tempo, é menor a quantidade de benzeno extraída no equilíbrio $\left(\mathrm{K}_{\mathrm{fh}}=301 \text { (benzeno) e } 2900 \text { (o-xileno }\right)^{17}$ ).

As discussões anteriores indicam que no trabalho experimental os perfis de extração devem ser estabelecidos, para serem obtém o tempo e as condições adequadas para o equilíbrio de extração. Definir estas condições constitui-se no desenvolvimento de um método SPME, discutido a seguir. 


\section{DESENVOLVIMENTO DE UM MÉTODO DE SPME}

A discussão que segue aplica-se ao desenvolvimento de um método de SPME em condições de equilíbrio (dispositivos para extração exaustiva só existem a nível de pesquisa ${ }^{7}$ ) e análise por CG, para a qual a SPME foi primordialmente desenvolvida. Este desenvolvimento pode ser considerado como constituído das etapas de extração e de transferência do material da fibra para análise cromatográfica. Na primeira etapa é essencial estabelecer os perfis de extração dos analitos; na segunda etapa deve-se otimizar a transferência do material extraído para a coluna cromatográfica e a resolução cromatográfica. A metodologia deste procedimento envolve a seguinte estratégia analítica.

$O$ conhecimento do problema analítico. Estabelecer quais os analitos de interesse e preparar uma amostra sintética a partir de seus padrões ou de compostos similares. Com esta amostra executa-se o primeiro passo da etapa de extração: avaliar o $t_{e}$ de cada analito, via de regra com mais do que um tipo de fibra (Tabela 1) e analisar os extratos por CG. Serão coletadas informações sobre:

- as condições cromatográficas (coluna, detector, etc) apropriadas para os analitos;

- qual recobrimento é mais adequado para os analitos;

- quais condições de extração (agitação, temperatura, extração direta ou de headspace, volumes do frasco de amostragem, da amostra e do headspace) são as mais convenientes;

- quais as condições para dessorção no injetor do cromatógrafo (que podem redefinir as condições cromatográficas);

- o procedimento experimental para obter os perfis de extração destes "analitos padrão".

Primeira aproximação do problema representado pela matriz: Trabalhar, como anteriormente, com amostras sintéticas dos analitos, ou os compostos que os representem, em concentrações similares às esperadas na matriz. Assim será possível avaliar:

- se é possível optar por fibra com recobrimento de menor espessura;

- se é possível extrair os analitos do headspace;

- se as condiçõos de extração e de cromatografia tem de ser redimensionadas;

- se os perfís de extração aplicam-se à concentrações próximas das reais.

Segunda aproximação do problema representado pela matriz: Simular a matriz, adicionando às amostras sintéticas componentes extra-analitos representativos daqueles que possivelmente existam na matriz real. Isto poderá revelar:

- se é possível operar com a SPME direta, pois componentes da matriz podem contaminar/deteriorar a fibra e/ou impedir a subsequente análise por CG;

- se as condições de extração anteriormente avaliadas tem de ser readaptadas;

- se é viável analisar simultaneamente todos os analitos, pois alguns podem demandar a extração do headspace e outros a extração direta (neste caso o método passa a ser substancialmente complexo).

- Trabalhar com a sua matriz real: todas as preocupações experimentais anteriores são passíveis de reavaliações e eventuais modificações.

- Validar o método. Discutido em Validação do Método. A estratégia acima aplica-se desde o preparo da amostra até a sua análise; no caso de SPME ela envolve tanto procedimentos básicos, aplicáveis a qualquer método analítico, quanto procedimentos próprios da SPME.

\section{SELEÇÃO DO MODO DE EXTRAÇÃO}

As opções são a SPME direta e de headspace. O fato da SPME direta não ser aplicável a matrizes aquosas contendo particulados e a matrizes sólidas evita trabalhos infrutíferos.
Por exemplo, na extração de humuleno e cariofileno de lúpu$10^{18}$ a opção natural foi a extração do headspace, por tratar-se de matriz sólida. Para matrizes aquosas "limpas" ambas alternativas mencionadas devem ser verificadas. Um critério geral é o de que a SPME de headspace é indicada para analitos de média e alta volatilidade ${ }^{12}$. No entanto, numa análise de COVs (compostos orgânicos voláteis) em água a SPME direta foi a melhor opção pois, com fibra PDMS $100 \mu \mathrm{m}$ as relações entre as quantidades recuperadas por extração direta e de headspace foram de 30:1 para cloreto de vinila, 13:1 para clorofórmio, 10:1 para benzeno e 6:1 para tolueno ${ }^{4}$. Portanto, eventualmente a SPME direta pode ser aplicada para compostos voláteis ${ }^{9,11}$.

\section{SELEÇÃO DO TIPO DE FIBRA}

As sugestões gerais de uso para as fibras comercialmente disponíveis relacionadas na Tabela 1 são úteis como ponto de partida, mas devem ser conferidas experimentalmente. Por exemplo, na Figura 9 mostra-se que a umidade, um fator relacionado com a característica da amostra, afeta a extração de acetona, etanol e isopreno de hálito humano ${ }^{19}$.

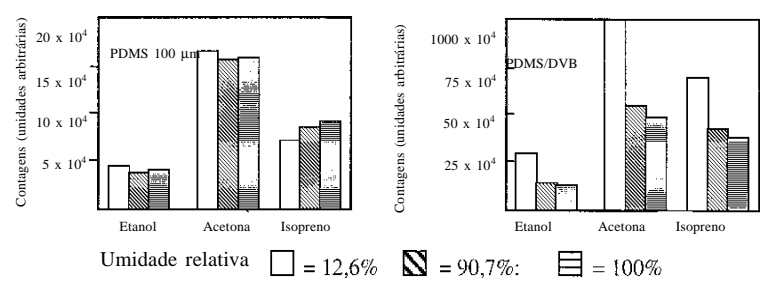

Figura 9. Efeito do tipo de recobrimento e umidade relativa sobre a quantidade de compostos extraídos de amostra gasosa (hálito humano).

Das fibras estudadas acima, a PDMS foi selecionada por ser menos afetada pela umidade, embora a PDMS / DVB extraísse maiores quantidades dos analitos. A literatura reporta usos e características de fibras (ver Apêndice B, p. 229-241 em²); estas informações também podem ser localizadas em notas técnicas dos fabricantes ${ }^{20}$.

\section{ESTUDO DOS PERFIS DE EXTRAÇÃO}

Estabelecer os perfis de extração é uma forma segura de avaliar a eventual necessidade de reciclagem de procedimentos que otimizem o tempo de extração. Entre os fatores passíveis de alteração estão a espessura da fibra e sua afinidade com os analitos, a agitação do sistema (Figura 5), a sua temperatura e o tipo de frasco utilizado (volume, formato e material de construção). Comparar os perfis de extração de analitos diferentes mostra qual o tempo mínimo para as extrações simultâneas numa amostra e quais as sensibilidades relativas entre os correspondentes analitos (Figura 8). Um exemplo de exploração das informações obtidas dos perfis de equilíbrio encontra-se na anteriormente citada extração de humuleno e cariofileno de lúpulo $^{18}$, onde o interesse era obter as razões entre as quantidades de humuleno e cariofileno (H/C). Dois procedimentos de SPME de headspace foram testados: (a) extrair depois de aquecer a amostra a $50^{\circ} \mathrm{C}$ por $12 \mathrm{~h}$ e (b) extrair quando a amostra atingisse a temperatura de $50^{\circ} \mathrm{C}$. Na Figura 10 os valores obtidos de H/C são comparados ao obtido por extração com vapor d'água, que é o método convencional para estas análises ${ }^{18}$.

No exemplo da figura 10 determinou-se que o tempo de extração adequado para humuleno e cariofileno era de $4 \mathrm{~h}$, com ou sem o pré-aquecimento da amostra, e que sem o pré-aquecimento a razão $\mathrm{H} / \mathrm{C}$ obtida $(2,75)$ é próxima ao valor medido com o método de extração por arraste com vapor d'água. Além disso, como com pré-aquecimento por $12 \mathrm{~h}$ a razão $\mathrm{H} / \mathrm{C}$ aumentava para cerca de 3 , supôs-se que 


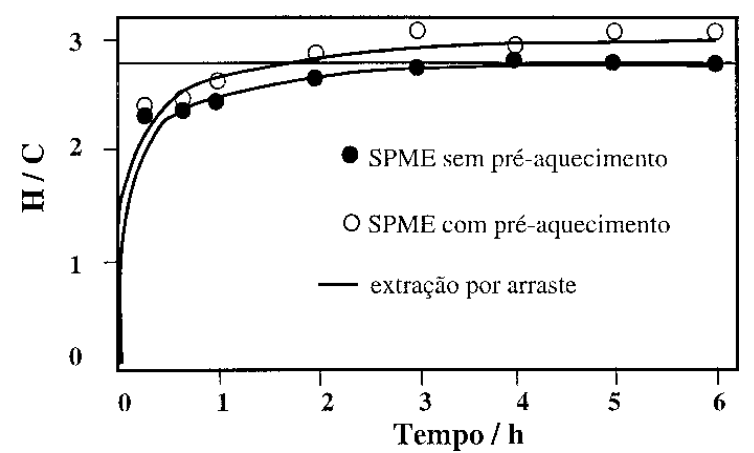

Figura 10. Razões humuleno / cariofileno para extrações SPME de uma amostra de lúpulo aquecida a $50^{\circ} \mathrm{C}$ sem e com um período de 12 $h$ de pré-aquecimento ${ }^{18}$. Também é mostrada a razão H/C obtida pela extração com arraste por vapor d'água.

este procedimento alteraria a amostra (o que foi confirmado e atribuído a oxidação do cariofileno). Informações específicas como as acima e as referentes às Figuras 5 e 8 podem ser obtidas da literatura ${ }^{22,23}$.

\section{SELEÇÃO DA TÉCNICA DE AGITAÇÃO}

Como mostrado na Figura 5, a otimização da agitação é fundamental para abreviar o tempo de extração. A agitação magnética, por sua simplicidade, é a mais comumente utilizada. Outras técnicas demandam dispositivos mais complexos: vibração da fibra, usada em injetor automático desenvolvido pela Varian; movimentação circular do $\operatorname{frasco}^{24}$; e sonicação, que diminui o tempo de equilíbrio mas pode adulterar a amos$\operatorname{tra}^{24-26}$. Em análises de gases os efeitos de agitação podem ser conseguidos utilizando-se a técnica de extração sob fluxo da amostra ${ }^{12,19}$

\section{OTIMIZAÇÃO DA DESSORÇÃO}

A dessorção é otimizada:

(a) Com a fibra colocada no centro da zona aquecida do injetor ${ }^{27}$.

(b) Com arraste rápido dos compostos dessorvidos da fibra, o que é conseguido usando-se no injetor um "liner" de pequeno diâmetro interno (geralmente $\mathrm{d}_{\mathrm{i}}=0,8 \mathrm{~mm}$ nos liners comerciais). Com a fibra inserida no liner é criada uma região de restrição, onde a velocidade do gás de arraste é aumentada sem necessidade de alterar a sua pressão, que depende das condições cromatográficas.

(c) Com o injetor em temperatura que seja um compromisso entre a permitida pela fibra e a volatilidade dos analitos.

Fundamentos da otimização da dessorção encontram-se na literatura $^{28}$

\section{OTIMIZAÇÃO DOS VOLUMES ENVOLVIDOS NA EXTRAÇÃO}

A otimização dos volumes envolvidos em SPME continua sendo objeto de estudos ${ }^{29,30}$, por depender de fatôres e parâmetros não contemplados nas equações 5 e 6 , como a agitação e o próprio volume do frasco de amostra (habitualmente, de 2 a $40 \mathrm{ml}^{31}$ ). O uso de frascos pequenos torna a otimização um processo bastante delicado ${ }^{29}$. Para simplificar esta discussão optou-se por um exemplo de avaliação de resultados, resultante de extração de headspace de clorofórmio, 1,1,1-tricloroetano e tetracloreto de carbono usando frascos de 4, 15 e $40 \mathrm{ml}$ e fibra PDMS $100 \mu \mathrm{m}^{32}$. Conforme mostrado na Figura 11, para $\mathrm{V}_{\mathrm{m}}=40 \mathrm{ml}$, para os três compostos a fração extraída $\left(\mathrm{n} / \mathrm{n}_{0}\right)$ tende aumentar conforme a razão $V_{h} / V_{m}$ diminui; a mesma tendência foi observada para $\mathrm{V}_{\mathrm{m}}=4$ e $15 \mathrm{ml}$.

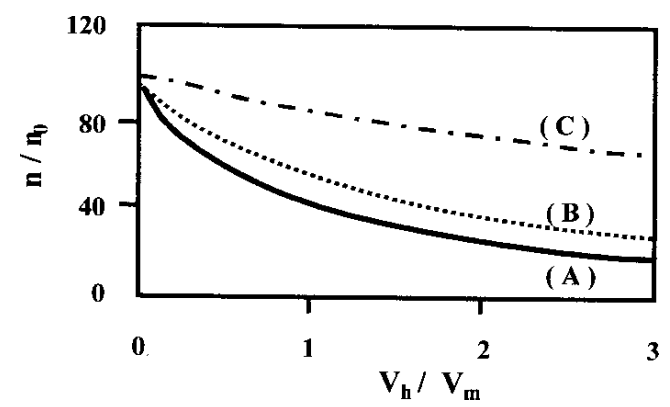

Figura 11. Efeito do volume do headspace sobre a quantidade de analito extraída. Frasco de $40 \mathrm{ml}$, fibra PDMS $100 \mu \mathrm{m}$. (A) clorofórmio, $K_{f m}=$ $400, K_{h m}=0,15$, (B) 1,1,1-tricloretano, $K_{f m}=2500, K_{h m}=0,7 e(C)$ tetracloreto de carbono, $K_{f m}=1000, K_{h m}=1,24$ (adaptada de 32).

$\mathrm{Na}$ Figura 11 o uso da razão $\mathrm{V}_{\mathrm{h}} / \mathrm{V}_{\mathrm{m}}$ é muito conveniente, porque como o volume do frasco é fixo, essa razão pode ser otimizada variando-se a quantidade de amostra. O uso da fração $\mathrm{n} / \mathrm{n}_{0}$ é analiticamente relevante, porque expressa a sensibilidade do método e fornece a sua recuperação. Na figura notam-se comportamentos diversos entre os analitos considerados, o que é atribuido às diferenças entre os valores de $\mathrm{K}_{\mathrm{fm}} \mathrm{e}$ $\mathrm{K}_{\mathrm{hm}}$ dos compostos, como discutido no ítem 5.2 (Figura 7).

\section{VALIDAÇÃO DO MÉTODO}

As estrategias gerais para validação de um método dependem, entre outros fatores, das amostras, dos propósitos analíti$\cos$ e da instrumentação disponível ${ }^{33}$. Ela pode envolver: estabelecimento de linearidade, recuperação (fração extraída dos analitos) e repetibilidade; comparação com métodos convencionais; avaliações com amostras-padrão e comparações interlaboratoriais e com resultados de análises por instituições independentes. Um procedimento importante da convalidação de um método SPME é aplicá-lo, assim como o(s) método(s) convencional a amostras reais, comparando-se os resultados - como exemplo, veja-se na Figura 10 que para um dos modos de extração SPME a razão H/C coincide com o valor obtido após extração por arraste com vapor; outros exemplos deste procedimento são descritos na literatura ${ }^{34-44}$. As comparações interlaboratoriais e confrontação com análises independentes são menos comuns; exemplos delas são encontradas nas refs. ${ }^{4,45,46}$.

\section{BREVE RESUMO BIBLIOGRÁFICO SOBRE SPME}

A SPME tem aplicações em áreas como análise ambiental e de solos, água, alimentos, produtos naturais e farmaceuticos, análise clínica e forense ${ }^{1}$. Sendo um técnica relativamente nova (da década de $90^{1}$ ) continua em consolidação ${ }^{22}$, tanto sob o aspecto de fundamentação teórica, quanto sob os de aplicações.

Na primeira descrição de extração por SPME os dispositivos de extração consistiam de microseringas de CG, adaptadas para conter pedaços de fibra ótica que podiam ser expostas e retraídas na agulha da seringa. O filme de PDMS, que recobria as fibras para resistência mecânica, foi testado como meio extrator demonstrando a potencialidade dessa microtécnica, com extrações diretas de soluções aquosas de hidrocarbonetos aromáticos, que foram quantificados por GC com limites de detecção de até $1 \mu \mathrm{g} . \mathrm{L}^{-1}$ e desvios-padrão relativos de até $6 \%$ entre replicatas ${ }^{47}$. Comprovada a potencialidade da SPME, iniciaram-se os estudos dos seus parâmetros operacionais bási$\cos ^{31,48}$. No primeiro ensaio de extração seletiva com fibra diferente da PDMS ${ }^{49}$ foram quantificados e identificados fenóis em solução aquosa por extração com fibras de $95 \mu \mathrm{m}$ de poliacrilato e análise por CG-EM (Cromatografia Gasosa com Detecção por Espectrometria de Massas). Ainda hoje, ampliar a diversidade dos tipos de fibras é uma necessidade; como 
exemplo, o desenvolvimento da fibra Carboxen/PDMS facilitou a extração compostos voláteis, como os de $\operatorname{aromas}^{50}$ e gases sulfurosos ${ }^{4}$.

Recentemente foi proposto um modelo matemático que permite estimar a concentração desse analito, a partir do seu fator de resposta para o detector por ionização em chama e a área do seu pico cromatográfico, obtido após uma extração por SPME de headspace ${ }^{51}$. Este estudo, baseado em experimentos com 71 compostos funcionalmente diversos, evidencia as vantagens de aplicar SPME na análise de voláteis biológicos. O modelamento matemático da dinâmica do processo de adsorção em SPME, em condições de agitação experimental demonstra que análises quantitativas podem ser efetuadas antes de ser atingido o equilíbrio de extração ${ }^{32}$. São relatados tempos para equilíbrio de até $1 \mathrm{~h}$ (SPME direta) e até 40 min (SPME headspace); os quais, pela modelagem estudada, podem ser substancialmente abreviados. Num estudo usando fibras PDMS, para quantificar no headspace hidrocarbonetos de petróleo presentes em água, é demonstrada a possibilidade do cálculo das $\mathrm{K}_{\mathrm{fm}}$ desses analitos a partir de sua retenção cromatográfica ${ }^{22}$. Num trabalho similar com seis tipos de fibras é sugerido que a quantificação a partir do headspace pode ser dífícil pela variabilidade da $\mathrm{K}_{\mathrm{fh}}$ dos analitos ${ }^{23}$. Foram propostos os modelamentos do equilíbrio de sorção e da cinética de extração utilizando como analitos 11 compostos orgânicos voláteis, considerando-se os efeitos salino (em água do mar) e efeitos de matriz devido à presença de ácidos húmicos ${ }^{52}$. Num estudo envolvendo extração de headspace em condições de fluxo, foi demonstrado que os tempos de equilíbrio são menores do os obtidos com extrações de headspace estático convencional, por minimização da dependência com a difusão do analito no $\mathrm{ar}^{12}$. Os fundamentos da amostragem dinâmica de ar também foram avaliados, concluindo-se que este tipo de amostragem pode ser realizada sem agitação ${ }^{12,19}$. A extração de aldeídos, pirazinas, piridinas e tiazóis (produtos da reação de Maillard) por PDMS $100 \mu \mathrm{m}$ e CBW/DVB $65 \mu \mathrm{m}$, incluindo avaliação do efeito salino, foi objeto de avaliação sistemática, em que se discutem vários fatores experimentais que afetam as extrações tanto para fins quantitativos quanto para qualitativos ${ }^{23}$. Num estudo sobre extração de pirazinas de cacau torrado foi evidenciado que o rendimento de extração é maior quando feita no headspace do sólido ao invés de no headspace de sua suspensão aquosa ${ }^{53}$. As condições de injeção splitless no CG foram exploradas, demonstrando-se, p.ex, que o tempo de dessorção no CG é importante na recuperação de analitos de diferentes volatilidades ${ }^{54,55}$. Em aromas de maçãs, 29 componentes foram extraídos e quantificados por PDMS $100 \mu \mathrm{m} / \mathrm{CG}-\mathrm{EM}^{37}$; menciona-se um efeito de matriz devido à competição dos analitos pela fibra, que pode afetar a condição de saturação da fibra. Na determinação de nitrocompostos utilizados como almíscares artificiais em vários tipos de cosméticos são discutidos efeitos de matriz para diversos tipos de cosméticos ${ }^{56}$.

Para a otimização de um método para quantificação de 31 aromatizantes típicos de tabaco foram testadas as fibras PDMS $100 \mu \mathrm{m}$, PA $65 \mu \mathrm{m}$, PDMS/DVB $65 \mu \mathrm{m}$, CBX/DVB $65 \mu \mathrm{m}^{57}$; observou-se pronunciado efeito de matriz e que fibras polares se mostraram as mais adequadas nas extrações. No mesmo trabalho, determinou-se que o efeito salino afeta de modo diferente a extração dos diversos analitos testados. A SPME de headspace foi aplicada, com resultados melhores do que a SPME direta, para análise quantitativa de componentes de aroma produzidos por bactérias derivados de carne ${ }^{34}$; as extrações com fibra PA foram melhores do que com PDMS, devido ao caráter polar (ácidos orgânicos) desses analitos.

Várias descrições de aplicação da SPME incluem valiosas informações sobre a comparação desta técnica com outras. Para a análise de constituintes dos aromas de refrigerantes tipo "cola", a SPME de headspace é comparada com o headspace dinâmico convencional seguido de adsorção em Tenax ${ }^{35}$. É demonstrado que a SPME é um método mais rápido, embora com o headspace dinâmico convencional tenha sido obtida maior sensibilidade e extração de maior variedade de compostos. Doze álcoois e estéres foram analisados em cerveja por SPME de headspace, usando fibra PA; na comparação com o headspace estático convencional houve boa correlação entre os dois métodos e maiores sensibilidades com SPME ${ }^{36}$.

Para identificação e quantificação por CG-EM de componentes de aromas de maçãs, a SPME de headspace ${ }^{37,38}$ foi comparada com o método convencional de headspace dinâmico ${ }^{39}$. O headspace de sucos de laranja foi estudado por SPME-CG-MS ${ }^{40}$ para identificar e quantificar 17 analitos; tradicionalmente estas análises são realizadas ${ }^{41-43}$ por headspace estático e dinâmico, arraste gasoso (gas stripping) ou purga e trapeamento A SPME de headspace para análise de aromas de queijos foi avaliada e comparada com o headspace estático convencional, demonstrando-se que a SPME extrai maior número de componentes dos aromas $^{44}$. A SPME de headspace permitiu a extração de 11 pirazinas em $10 \mathrm{~min}$, comparando-se muito favoravelmente com os tempos de extração de 17 horas de outros métodos ${ }^{58}$.

\section{AGRADECIMENTOS}

À FAPESP pelo suporte a dois projetos que tornaram possíveis os estudos que levaram ao presente artigo.

\section{REFERÊNCIAS}

1. Arthur, C. L.; Pawliszyn, J.; Anal. Chem. 1990, 62, 2145.

2. Mc.Nair, H. M.; Miller, J. M.; Basic Gas Chromatography; Wiley-VCH; New York, NY, 1997; p.11.

3. Pawliszyn, J.; Solid Phase Microextraction: Theory and Practice; Wiley-VHC; New York, NY, 1997; p. 3.

4. Shirey, R. E.; Mani, V.; Pittcon Connference; Atlanta, GA, 1997.

5. Supelco Inc.; Chromatographic Products (catálogo); Supelco, Bellefonte, PA, 1996; p. 373.

6. Pawliszyn, J.; op. cit.; p.118.

7. Pawliszyn, J.; op. cit.; p.98.

8. Alexandrou, N.; Pawliszyn, J.; Anal. Chem. 1989, 61, 2770.

9. Zhang, Z; Pawliszin, J.; Anal. Chem. 1993, 65, 1843.

10. Pawliszyn, J.; op. cit.; p. 212.

11. Louch, D.; Motlagh, S.; Pawliszyn, J.; Anal. Chem. 1992, 64, 1552.

12. Martos, P. A.; Pawliszyn, J.; Anal. Chem. 1997, 69, 206.

13. Castellan, G. W.; Physical Chemistry; $2^{\mathrm{a}}$ ed.; AddisonWesley; Reading, MA, 1972; p.689.

14. Pawliszyn, J.; op. cit.; p.66.

15. Pawliszyn, J.; op. cit.; p.82.

16. Pawliszyn, J.; op. cit.; p.80.

17. Zhang, Z.; Pawliszyn, J.; J. Phys. Chem. 1996, 100, 17648.

18. Field, J. A.; Nickerson, G.; James, D. D.; Heider, C.; J. Agric. Food Chem. 1996, 44, 1768.

19. Grote, C.; Pawliszyn, J.; Anal. Chem. 1997, 69, 587.

20. Supelco Inc.; Index to Solid Phase Microextraction (SPME) Literature; www.sigma-aldrich.com/SAWS.nsf/ Pages/fb_spmelit .

22. Saraullo, A.; Martos, P. A.; Pawliszyn, J.; Anal. Chem. 1998, 69, 1992.

22. Schäfer, B.; Hennig, P.; Engewald, W.; J. High Resolut. Chromatogr. 1997, 20, 217.

23. Colleman III, W. M.; J. Chromatogr. Sci. A 1997, 35, 245.

24. Pawliszyn, J.; op. cit.; p.109.

25. Gorecki, T.; Pawliszyn, J.; Anal. Chem. 1996, 68, 3008.

26. Wang, Y.; Bonilla, M.; McNair, H. M.; J. High Resolut. Chromatogr. 1997, 20, 213.

27. Pawliszyn, J.; op. cit.; p.113.

28. Zhang, Z.; Poerschmann, J.; Pawliszyn, J.; Anal. Comunn. 1996, 33, 219

29. Pawliszyn, J.; op. cit.; p.60. 
30. Gorecki, T.; Pawliszyn, J.; Analyst 1998, 123, 1079.

31. Motlagh, S.; Pawliszyn, J.; Anal. Chim. Acta 1993, 284, 265.

32. Ai, J.; Anal. Chem. 1997, 69, 120.

33. Huber, L.; $L C$-GC 1998, 16, 148.

34. Vergnais, L.; F. Masson, F.; Montel, M. C.; Berdagué, J. L.; Talon, R.; J. Agric. Food. Chem. 1998, 46, 228.

35. Elmore, J. S.; Erbahadir, M. A.; Motlran, D. S.; J. Agric. Food Chem. 1997, 45, 2638.

36. Jelén, H. H.; Wlazly, K.; Wasowicz, E.; Kaminski, E.; J. Agric. Food Chem. 1998, 46, 1469.

37. Song, J.; Gardner, B. D.; Holland, J. F.; Beaudry, R. M.; J. Agric. Food Chem. 1997, 45, 1801.

38. Matich, A. J.; Rowan, D. D.; Banks, N. H.; Anal. Chem. 1996, 68, 4114.

39. Pinnel, V.; Rossels, P.; Vandegans, J.; J. High Resolut. Chromatogr. 1995, 18, 309.

40. Steffen, A.; Pawliszyn, J.; J. Agric. Food Chem. 1996, 44, 2187.

41. Moshonas, M. G.; Shaw, P. E.; J. Agric. Food Chem. 1994, 42, 1525 .

42. Paik, J. S.; Venables, A. C.; J. Chromatogr. A 1991, $540,456$.

43. Shaw, P. E.; Buslig, B. S.; Moshonas, M. G.; J. Agric. Food Chem. 1993, 41, 809.

44. Chin, H. W.; Bernhard, R. A.; Rosemberg, M.; J. Food Sci. 1996, 61, 1118.
45. Gorecki, T.; Pawliszyn, J.; Analyst 1996, 121, 1381.

46. MacGillivray, B.; Fowlie, P.; Pawliszyn, J.; J. Chromatogr. Sci. 1994, 32, 317.

47. Arthur, C. L.; Potter, D. W.; Buchholz, K. D.; Motlagh, S.; Pawliszyn, J.; LC-GC 1992, 10, 656.

48. Louch, D.; Motlagh, S.; Pawliszyn, J.; Anal. Chem. 1992, 64, 1187.

49. Buchholz, K. D.; Pawliszyn, J.; Environ. Sci. Technol. 1993, 27, 2844.

50. Augusto, F.; Montero, L.; Pini, G. F.; Valente, A. L. P.; Pawliszyn, J.; Livro de Resumos - IX ENQA; São Carlos, SP, 1997; resumo 049.

51. Bartelt, R. J.; Anal. Chem. 1997, 69, 364.

52. Dewulf, J.; Langenhove, H.; Everaert, M.; J. Chromatogr. A 1997, 761, 205.

53. Pini, G. F.; Augusto, F.; Valente, A. L. P.; Brito, E. S.; Garcia, N. H. P.; $21^{\text {st }}$ ISCC\&E, Park City, UT, 1999.

54. Okeyo, P.; Snow, N. H.; LC-GC 1997, 15, 1130.

55. Okeyo, P.; Snow, N. H.; J. High Resolut. Chromatogr. 1997, 20, 77.

56. Struppe, C.; Schäfer, B.; Engewald, W.; Chromatographia 1997, 45, 138.

57. Clark, T. J.; Bunch, J. E.; J. Agric. Food Chem. 1997, $45,844$.

58. Ibañez, E.; Bernhardt, R. A; J. Sci. Food Agric. 1996, 72,91 . 